\title{
Self-Regulated Learning Activities: Supporting Success in Online Courses
}

\author{
Maureen Snow Andrade \\ Utah Valley University \\ USA
}

\section{Introduction}

Although most higher education institutions offer some form of distance education (Parsad \& Lewis, 2008), learners may struggle with this mode of learning due to insufficient independence and discipline. Success in these contexts requires learner self-regulation, or the ability to control the factors and conditions that affect learning (Dembo, Junge, \& Lynch, 2006). The Model of Self-Regulated Distance Learning (Andrade \& Bunker, 2009, 2011b) has been successfully applied to online distance English language courses to increase learners' self-regulation, capacity for autonomy, course persistence, and language proficiency (Andrade \& Bunker, 2011a). The model, based on the theories of transactional distance (Moore, 1972, 2007) and self-regulated learning (Schunk \& Zimmerman, 1994; Zimmerman, 1994; Zimmerman \& Risemberg, 1997), provides a framework to guide course designers and teachers in helping learners develop self-regulated learning behaviours as they master course content. The model is applicable to any course or content area. This chapter briefly reviews the theoretical underpinnings of the model and research that demonstrates its effectiveness. It then shares approaches and activities that can be embedded into distance courses to meet learners' diverse needs and educational backgrounds. These activities are illustrated with examples of distance English language courses and learners.

\section{Theoretical model}

Moore's theory of transactional distance involves three components: structure, dialogue, and autonomy. Structure consists of the objectives, assignments, due dates, textbook, schedule, and other organizational elements in a course. Dialogue involves interaction with the teacher, peers enrolled in the course, and agents of the institution. It might include email, telephone, video conferences, and written and oral assignment feedback. Autonomy has been defined numerous ways, but can best be conceptualized as involving two key components - choice and capacity. Choice refers to the learner's freedom to make decisions about learning, specifically setting goals, selecting materials, determining how and what to study, and evaluating performance (e.g., see Holec, 1981; Hurd, 1998b, 2005; Little, 1991, White, 2003). When learners do not have much input related to a course, the level of autonomy is low. In these cases, structure is high, meaning that decision-making about what and how to learn are controlled within the course or by the teacher. 
Capacity refers to the learner's ability to be self-directed in terms of being an active learner, taking control, and awareness and use of learning strategies (e.g., see Garrison, 2003; Holec, 1981; Hurd, 1998a; Vanijdee, 2003; White, 2003). When learners have the capacity to be autonomous, they are more likely to achieve success in a distance learning context. When structure and dialogue are high, the "transactional distance" (Moore, 2007, p. 90) between the learner and the teacher decrease; the level of autonomy also decreases. Although high levels of structure and dialogue may provide necessary scaffolding and support for learners, these components should ideally lead to the learner building capacity for independence and needing less structure and dialogue to be successful.

Self-regulated learning is closely related to capacity as it involves learner self-direction and responsibility. It provides a framework for how learners can control the learning process. Self-regulated learning involves six dimensions: motive (e.g., reasons for learning, goals, self-talk, rewards/punishments), methods (e.g., learning strategies), time (e.g., time management, when to study), physical environment (e.g., identification and elimination of distractors), social environment (e.g., help, collaboration, communication), and performance (e.g., evaluation, reflection, goal revision) (Dembo et al., 2006; Schunk \& Zimmerman, 1994; Zimmerman, 1994; Zimmerman \& Risemberg, 1997). Learners who manage these dimensions and show evidence of being self-regulated are academically successful (Dembo et al., 2006). The term self-regulated learning has some advantage over the concept of autonomy because it emphasizes how to develop responsibility for learning and related behaviours. The dimensions provide a specific structural framework upon which to base course activities and strategy instruction. Self-regulated learning encompasses "the practical steps taken by learners to manage their own learning" (Hurd, 2005, p. 10).

Figure 1 depicts how interaction with structure and dialogue, course content, and related self-regulated learning activities contribute to the development of self-regulation and learner success (e.g., see Andrade \& Bunker, 2009, 2011a, 2011b). Learners begin a course with initial levels of self-regulated learning, commitment, and language proficiency (or knowledge of course content). In the English language courses described in this chapter, dialogue is provided through instructor feedback, e-mail, discussion groups, and live tutoring (the latter offers interactive language practice). Structure occurs through the study guide with instructions and links to course materials, the calendar with assignment due dates, audio and video presentations, and the textbook. Self-regulated learning activities, designed to provide goal-setting, application, and reflection opportunities, are included for each of the six dimensions. As students work with the course materials, learn and practice the language, and participate in self-regulated learning activities, they increase their selfregulation, capacity to be responsible and make appropriate choices with decreasing amounts of guidance, likelihood of persisting, and language proficiency or subject area knowledge. The model advances the practice of distance learning by providing a framework, based on established theories, by which to enhance learner success.

The model has the potential to positively affect distance learning in a variety of contexts and disciplines. Although some distance courses have utilized or studied self-regulated learning components such as motivation, reflection, metacognition, and goal setting to aid student success (e.g., see Bothma \& Monteith, 2004; Chang, 2005; Hurd, 2000, 2005; Murphy, 2005; Tobias, 2006; Thang, 2005; van den Boom, Pass, \& van Merrienboer, 2007), the framework depicted in Figure 1 and as described by Andrade and Bunker (2009, 2011a, 2011b) provides 


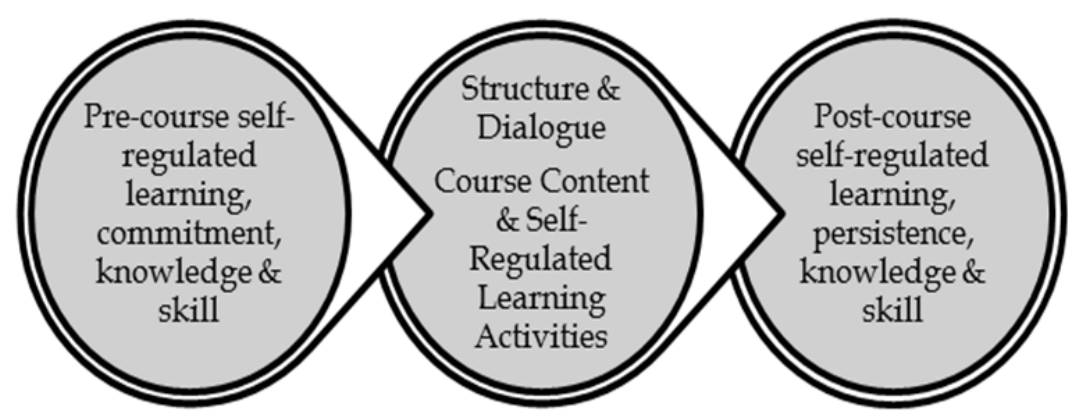

Fig. 1. Steps to self-regulation for distance learners.

designers, teachers, and students with guidance for addressing needs, strengthening weaknesses, and realizing success. The model is applicable to any content area or course. Course designers must consider the six dimensions of self-regulated learning and how to integrate them into course materials to develop and enhance learner responsibility.

\subsection{Effectiveness of the model}

A qualitative study consisting of 20 distance English language learners enrolled in a high intermediate level reading/writing course provides evidence of the model's effectiveness (Andrade \& Bunker, 2011a). Data was collected through reflective journals in which learners reported increased self-regulation, persistence, and English proficiency. As learners participated in the self-regulated learning and language activities in the course, they reflected on their performance in their journals, specifically their goals and strategy use. The self-regulated learning dimension of performance, or monitoring and evaluating progress in order to refine goals, was the primary purpose of the assignment. The journals were submitted to the teacher at various points during the course.

An analysis of these journals indicated a number of themes related to self-regulated learning and the dimensions. Learners reported that they had increased responsibility for their learning in the following ways: identifying their purpose for learning and understanding the importance of setting and achieving goals (motive), applying various study strategies (methods of learning), tracking and prioritizing their use of time (time), identifying appropriate times and places for study (physical environment), and recognizing that seeking help from tutors and teachers is a positive behaviour (social environment). The dimension of performance was embedded in the journal assignment itself.

Autonomy in the course was supported as learners had a choice of self-regulated learning activities based on an initial survey that helped them identify their strengths and weaknesses related to the dimensions. Learners selected an initial dimension on which to focus and corresponding activities to assist them in developing needed strategies. For instance, for the dimension of social environment, learners could choose from four activities-seeking help, preparing for a tutoring appointment, preparing for a teacher conference, or interacting with classmates. Choices related to the dimension of time included recording activities for 24 hours, prioritizing activities, evaluating time use, and organizing time. (More information about these activities is included in the Approaches and 
Activities section of the chapter.) Leaners were also offered relevant activities for the dimensions of motive, methods of learning, and physical environment. As they completed the activities of their choice and evaluated their performance (the sixth dimension of selfregulated learning), they revised their goals, set new goals, and continued to monitor their progress. They were required to do one activity each week and report on the experience in their learner journals, which they submitted to the teacher. When they felt they had made sufficient progress with one dimension, they could work on another. They had a variety of choices involving the dimensions, the activities, and the number of activities they participated in for each dimension.

The survey and related activity choices modelled the idea of taking responsibility for learning outcomes rather than depending on direction from the teacher. Structure was provided, as mentioned earlier, through various course components (e.g., study guide, calendar, due dates) as was dialogue in the form of announcements, e-mail reminders and assignment feedback, but choices were provided and the amount of structure and dialogue given varied across learners with the teacher being mindful of supporting the development of self-regulated learning.

A key structural element of the course was the study guide, which provided objectives, an overview of course content and tasks for each week, an estimate of the amount of time it would take to complete readings and assignments, instructions, study tips, and links to course materials, which were available in the learning management system. Icons in the study guide represented the various elements of the course such as "communicate," "self-check," "submit assignments," and "tests and quizzes." These icons were easily recognized and used consistently to help learners identify the various sections of the study guide and corresponding information. The study guide served as the teacher's voice in the course and was comparable in many ways to what a teacher would say in the classroom to instruct and support learners. Dialogue was sometimes provided to the entire class, as in the case of general feedback about an assignment or clarifications of an upcoming task, but it was also individualized in the form of e-mails to learners who were behind schedule or missing assignments, for instance. Thus, structure, dialogue, and autonomy were variables in the course that were managed in such a way as to support the learner yet promote self-regulation.

Overall, the study demonstrated that the model, designed to increase learners' levels of selfregulation and proficiency in the content area (in this case, English language ability) through interaction with course materials, self-regulated learning activities, and varying amounts of structure and dialogue, was effective in helping learners overcome challenges related to the distance learning mode. Learners reported that the self-regulated learning activities resulted in higher test scores and grades and improved learning skills and English proficiency. The following quotation illustrates:

Actually, there are many choices and strategies to use in this distance education course. Those include daily schedule, using study guide and text book, place to study, strength and weaknesses being a language learner, and getting help. According to my experience these are the important factors that can help me in this online course.

Limitations of the study include self-reported data and a small sample size. One of the findings that must be addressed in future iterations of the course is learners' depth of reflection and the conceptualization of goals. Some learners formed very broad goals such as 
improving their vocabulary and grammar or becoming a better reader, but did not identify specific sub goals or strategies related to these general areas. This can be addressed through teacher feedback to the learner journals as well as the inclusion of additional examples of goals, sub goals, and strategies within the course. However, overwhelmingly, students demonstrated not only awareness, but clear understanding, of the six dimensions of selfregulated learning and how to apply them to their English language studies. Related to methods of learning, one learner indicated: "I preview the course materials before I begin working on each unit (Study Guide, textbook, Blackboard); I will look at the assignments that will be due before I start working in each unit." Others indicated plans to apply the components of self-regulated learning beyond the course: "I'll keep applying them [selfregulated learning strategies] into every phase of my learning journey."

\section{Approaches and activities}

Learners' diverse needs, including linguistic, cultural, and educational backgrounds, must be considered when planning course content and activities. Learners from countries across the globe are enrolled in the distance English language courses described in this chapter. Countries include Norway, Nigeria, China, Mongolia, Cambodia, India, Indonesia, the Philippines, Thailand, Japan, Korea, Taiwan, Hong Kong, Saipan, Tonga, Kiribati, Papua New Guinea, the Dominican Republic, and Chile, to name a few. Course design must take into account how to accommodate learners from various time zones, with differing levels of computer access and literacy, English language proficiency, study skills, and familiarity with distance learning. Perhaps the greatest differences we have encountered among learners is their technological knowledge base, which ranges from those who are true digital natives to those who need to access a computer at an internet café or get help from someone they know in order to navigate course technology. Knowing this, our courses are designed to accommodate a range of skill levels and largely focus on the use of basic Word processing tools and PDF documents to accommodate variations in internet speed, web accessibility, equipment, and software.

Due to cultural backgrounds and educational experiences, learners have a range of expectations for learner and teacher roles, which affect the learning process. One of the situations we have encountered is that many learners, across countries and cultures, are accustomed to teacher-centered instruction. Distance learning requires that learners possess a degree of independence and discipline. Thus, the idea of self-regulated learning, choice in activities, and monitoring performance may be new to learners. Differing cultural backgrounds also serve as the basis for interesting perspectives on readings and related discussions.

Beyond this, learners also have diverse purposes, concerns, and individual situations. Some learners can work on a course daily while others may only be able to access it on a weekly basis due to employment situations. This section focuses on approaches and activities for addressing learners' needs and assisting their development as self-regulated learners, and consequently, their success in distance course work.

\subsection{Preliminary design decisions}

Prior to designing actual course activities, and particularly those specific to self-regulated learning, other decisions must be made. One of the first of these is to determine whether the 
course will be synchronous (learners progressing through the course together, often with scheduled whole or small group activities via text and voice chat, video, television, or telephone) or asynchronous (learners doing assignments on their own with interaction activities not dependent on learners connecting simultaneously to course learning systems). With learners from all over the world, or at least across several time zones, which is typical of many distance learning contexts, an asynchronous approach may be appropriate although some synchronous activity can be built in through live peer or tutor interactions that accommodate learners' time zones and schedules. If regular interaction and fixed assignment due dates are characteristic of the course and learners are expecting to work independently without interaction, however, this will affect their reactions and adjustment to the course. To address differing expectations, information about course design and content must be clearly communicated prior to enrollment and after the course begins.

Course designers and instructors must also have a sense of prospective learners' access to and familiarity with technology. In cases where learners have challenges with power outages, expensive fees for internet use, or limited computer access, printed materials can be provided or other accommodations made. Some learners in our courses only have access to a computer and the internet once a week. We addressed this by providing a printed study guide and textbook (to accommodate lack of available, on-going computer access and power failures), and a CD-ROM (so as to not be dependent on the internet). Learners can work from these materials and do word processing and assignment uploads when they have access to a computer at an internet café, place of employment, or friend's home. Before they enroll, learners should be informed of the types of technology they will need to use (i.e., webcams, learning management systems, live interaction tools) so that they will be prepared with the necessary skills for the course from the beginning and will not fall behind and become frustrated due to unfamiliarity with technology-based tasks and learning systems. If learners do not have these skills, designers and instructors can provide related tutorials in the first week or so of instruction and gradually introduce course assignments and their related formats and technology on an on-going basis.

Another key area to address, as it impacts learners' reactions to and attitudes about selfregulated learning course components, is views about learning and learner/teacher roles. Learners may be accustomed to either a passive or an active role, summative rather than formative assessments, a negative or positive opinion of help seeking, teacher-centered or learner-centered instruction, dependence on an authority figure or independence, an external or internal source of motivation, rote learning as opposed to critical thinking, face to face interaction in contrast to technology-based social networking, and an externally set daily learning schedule rather than a variable self-created schedule. These factors all have an impact on student learning and success.

To address these cultural, educational, and individual differences, perspectives, and dispositions in the learning environment, the course designer and instructor must be aware of and ready to accommodate and ameliorate factors that affect academic achievement and successful learning outcomes. The institutional infrastructure (i.e., technology help, information sources, learning assistance) must also be designed to provide needed support. Familiarity with learners' backgrounds and expectations is critical prior to course design and can be accomplished through a needs analysis. If not part of the course itself, an assignment that asks learners to share previous experiences, expectations, motivations for 
taking the course, and goals should be arranged by the instructor. This type of activity may be introduced as part of the motive dimension of self-regulated learning. In any case, course technology, content focus, and learning philosophies (including the emphasis on selfregulated learning) must be provided to learners preliminary to enrollment and early on in the course to prevent surprises and ensure the course is a good fit. It should also be addressed on an on-going basis as learners interact with each other and the instructor through discussion boards, presentations, e-mail communications, reflective journals, and live tutorials, as applicable.

\subsection{Self-regulated learning activities}

Possible types of activities corresponding to the six dimensions of self-regulated learning are indicated in Table 1. These have been used in distance English language courses. Course designers and teachers must consider student needs and specialized content characteristics as these will inform the choice, design, and structure of the activities. For instance, distance language learning has always been more problematic than acquiring knowledge in other subjects due to the need for interaction (Hurd, 2006). Second language acquisition theory indicates that learners must not only have comprehensible input (Krashen, 1985) (i.e., sources of reading and listening appropriate to the learner's proficiency level), but also

\begin{tabular}{|l|l|}
\hline Motive - Why? & $\begin{array}{l}\text { Purpose: to determine reasons for learning; analyze strengths and } \\
\text { weaknesses; set goals } \\
\text { Activities: diagnostic instruments; surveys; reflection; discussion } \\
\text { and video posts; live interactive conferences; self-talk analysis; value } \\
\text { identification }\end{array}$ \\
\hline $\begin{array}{l}\text { Methods of } \\
\text { Learning - How? }\end{array}$ & $\begin{array}{l}\text { Purpose: to expand knowledge and use of effective learning } \\
\text { strategies; improve long-term memory \& retrieval } \\
\text { Activities: evaluation; use of course materials; discipline-specific } \\
\text { learning strategies; scaffolding \& modeling; resources \& guides; } \\
\text { study skill tips }\end{array}$ \\
\hline Time - When? & $\begin{array}{l}\text { Purpose: to improve time management; increase self-esteem and } \\
\text { sense of competence } \\
\text { Activities: analysis of use of time; logs and records; prioritization }\end{array}$ \\
\hline $\begin{array}{l}\text { Social Environment } \\
\text { - With Whom? }\end{array}$ & $\begin{array}{l}\text { Purpose: to utilize sources of help; seek collaboration; improve } \\
\text { communication } \\
\text { Activities: e-mail; chat; social networking; blogs; live conferencing; } \\
\text { learn from experts and successful peers; modeling; role play }\end{array}$ \\
\hline $\begin{array}{l}\text { Physical } \\
\text { Environment - } \\
\text { Where? }\end{array}$ & $\begin{array}{l}\text { Purpose: to restructure the physical environment to make it } \\
\text { conducive to study } \\
\text { Activities: analysis of environment; distracter classification; } \\
\text { restructuring of the environment }\end{array}$ \\
\hline $\begin{array}{l}\text { Performance } \\
\text { - What? }\end{array}$ & $\begin{array}{l}\text { Purpose: compare performance and goals; analyze \& revise goals } \\
\text { Activities: regular reflections; self-progress reports; teacher and peer } \\
\text { feedback }\end{array}$ \\
\hline
\end{tabular}

Table 1. Example self-regulated learning activity types. 
opportunities for output (Swain, 1995), or the opportunity to negotiate meaning, make input comprehensible, get feedback, and modify discourse to effectively communicate (Long, 1996). Additionally, English language learners are often accustomed to passive learning modes rather than critical thinking, synthesis of knowledge, risk-taking, and learner responsibility, and thus must be encouraged to engage, interact, and use the language for communicative and problem-solving purposes. Foreign language courses in the Open University system in the U.K. contain strategy instruction to promote learner autonomy and success (Hurd, 2005), recognizing the challenges of distance learning and the potential unfamiliarity of learners with needed language learning and general study strategies. Regardless of content area, course activities supportive of learner success, in the form of selfregulated learning, can be embedded in the course.

Recognizing the needs of distance learners, many of whom are non-traditional in that they are older, employed, responsible for dependents (e.g., see Chen, Gonyea, \& Kuh, 2006), unfamiliar with technology-based learning, returning to education after time away, and may have misgivings not only about the distance format but also their ability to be successful, self-regulated learning activities can be designed to strengthen learner responsibility, increase knowledge and application of strategies, and alleviate fears. In the case of distance English language learners, we carefully designed activities to engage students in practicing English as they increase their levels of self-regulation. The activities focus on learning strategy awareness and application and provide opportunities for input and outputrequired components of language acquisition; in this way, content learning needs and selfregulated learning development complement each other.

Course designers may also want to provide learners with an array of activities from which to select in order to support the development of autonomy. Online distance courses lend themselves well to learner choice. To implement this, an assessment can be included that helps learners identify their strengths and weaknesses pertaining to the six dimensions of self-regulated learning. They can then select appropriate activities to address areas of weakness. At various intervals during the course, learners should reflect on their performance related to course content and their progress with the dimensions to determine how they might adjust their goals and associated methods of learning.

Our 15-week high intermediate level reading/writing course focuses on the development of language skills for academic purposes as most of our learners have the goal of pursuing post-secondary studies in an English-speaking country. For each level of language proficiency (i.e., low intermediate to high advanced), learners can choose from skill-based courses such as reading, writing, listening/speaking, or a content-based language course (e.g., biology, religion). The learning objectives for the high intermediate reading/writing course, as an example, focus on comprehension of academic readings through building vocabulary knowledge and reading strategies (e.g., previewing, finding the main idea, skimming and scanning, recognizing inferences and opinions, synthesizing and applying information, using graphic organizers, understanding word forms and grammatical constructions, etc.), and improving their writing ability in terms of organization, development of ideas, and grammatical accuracy at the paragraph and short essay level.

The students are also assigned study partners and groups and use the technology available in the learning management system such as e-mail, chat, and discussion forums to interact and practice their language by responding to ideas and exercises based on the course materials. 
The technology-enhanced interactions are introduced gradually and varied throughout the course as are the study partners and groups. An initial assignment involves learners creating a home page within the learning management system and posting an introductory video clip or a written introduction and picture of themselves. They also participate in a live weekly interactive tutoring session in which they discuss an assigned topic and ask logistical questions about the course. Learners take an initial placement test that indicates their language proficiency level (i.e., low/high intermediate or low/high advanced). They also take reading, writing, and vocabulary pre- and post-tests and have unit tests measuring the reading skills they have practiced. They submit various drafts of writing assignments for each unit in the course and receive feedback from a peer tutor and the instructor using a word processing tracking tool. The writing assignments are scored with a rubric.

The course begins with a learner self-assessment of the dimensions. From there, learners choose an initial dimension on which to focus and activities within that dimension. They complete a self-regulated learning activity each week and write a journal reflection. Instructors respond to the content of the journal but not to the language use as the purpose of the activity is to gain fluency in writing, have a specific purpose for communicating, and above all, to express understanding and application of the dimensions. The instructors score the journals according to a rubric which emphasizes the depth and thoroughness of the reflection and overall ability to communicate. Half way through and at the end of the course, learners focus on the dimension of performance by reviewing their success at attaining their goals and determining how to make adjustments. In this way, language practice (e.g., writing) and self-regulated learning development complement each other.

The next section outlines practical, easy-to-implement activities for distance language courses with ideas for how these can be applied more broadly. Each dimension is explicated and illustrative examples provided regarding how learners can develop related skills.

\subsubsection{Motive}

Motive is conceptualized as purpose for learning. It involves the learner determining reasons for enrolment in a specific distance course and what the learner hopes to attain as a result. It also encompasses the source of motivation - internal or external. Learners often believe that the instructor is responsible for motivating them (Dembo \& Eaton, 2000) rather than recognizing that self-motivation leads to greater levels of achievement. Related to this dimension, learners identify their motive for learning, set specific goals, examine their selftalk (i.e., internal thoughts and verbalizations regarding beliefs in their ability to be successful), and consider possible rewards and punishments for their behaviours (Dembo \& Eaton, 2000; Dembo et al., 2006; Dembo \& Seli, 2008). Learners who enrol in distance courses do so for a variety of reasons, including convenience, preference for self-paced learning, and a desire for independence (e.g., see Chen et al., 2006). These reasons for choosing distance learning must be accompanied by goal setting and other strategies that help learners sustain and increase levels of motivation. Distance learners may not have the benefit of external sources of motivation, such as the incentive of being prepared before facing their teacher and peers in class several times a week, thus it becomes easier to relax and lose momentum.

\subsubsection{Reasons for learning}

One activity we have used to help learners identify their reasons for learning is to listen to a video clip of an inspirational speaker and his experiences learning English. The speaker is a 
well-respected and known figure to the learners. He explains how he grew up in East Germany and learned Russian in school (Uchtdorf, 2006). The Russian language was difficult, but when his family moved to West Germany and he was required to learn English, he found it to be impossible until he realized that to attain his dream to be an airline pilot, he would need to be fluent in English. His motivation, persistence, desire, and ability to learn English completely changed.

Learners' English language skills are developed as they listen to and read excerpts from the talk and respond to specific questions in writing. They reflect on the content of the speech and apply it to their own English language learning situations. As they respond to the speakers' ideas and reflect on their reasons for learning, they identify with greater clarity the depth and source of their motivation. For example, one learner stated:

From doing this activity, I learnt that setting different goals affect our life. Before setting goals, we need to weigh many things. For example: ability and times.... Setting goals is meaning I have a dream, an ideal. It means that I decided to make more effort for my future. Setting goals is also helping me to recognize what I want to do. Let me remember how important of my future.

Autonomy is supported as learners choose to either listen to or read the talk, and to listen to or read it in its entirety rather than only the clip in the lesson. For other content areas or academic disciplines, autobiographies, biographies, or recordings of professionals, experts, researchers, and theorists might be used in a similar way. Learners can engage in live chat or discussion board activities related to their response to these sources of information.

\subsubsection{Goal setting}

Goal setting is critical to the dimension of motive and the basis for strategy development related to the other dimensions. For instance, English language learners might set a goal to increase their active use of academic vocabulary. This broad goal would be accomplished through sub goals such as becoming familiar with the Academic Word List, assessing knowledge of words on the list, identifying research-based methods of learning vocabulary, and then selecting one or two of these methods to apply to vocabulary acquisition. Specific strategies might include use of word cards, study of word parts, or dictionary use. These would be implemented according to guidelines for effective ways to utilize these strategies.

One of the self-regulated learning activities in our course provides learners with the opportunity to identify their values, or principles that guide their lives, and how these values are related to their long-, intermediate-, and short-range goals. They determine if and how these values are related to the course and improving their English language proficiency. In their learner journals, they write a description of their experience working through the guiding questions (i.e. what they learned about their values, which values are most important to them, which values relate most closely to the content of the course, why it is important to identify values before setting goals, and how values and goals are related to motive). They then identify appropriate goals and timelines for goal accomplishment. Related to goal setting, one learner commented:

The values that are important to me are as follows: family, God, service, education, and self-respect. The value that is the most important to me in this course is education. This course helped me write English accurately before getting in to the college.... The reasons 
I need to know my goal is that I would like to set each step to accomplish the goal I set

.... I will try my best to study harder. [This activity] woke me up to study hard.

Goal-setting can help learners in any course identify what they seek to accomplish through the course and the incremental steps they must take to achieve their desired end result.

\subsubsection{Methods of learning}

Methods of learning help learners acquire information and store it in long-term memory. High-achieving learners possess a variety of learning strategies and know how to use them effectively (e.g., see Dembo \& Eaton, 2000; Dembo et al., 2006; Dembo \& Seli, 2008). They understand that using one or two strategies in all situations is ineffective. Learning methods range from those that are less beneficial such as rehearsal, or copying notes, reciting, and underlining, to those that support making connections between new material and previously learned information. The latter include elaboration, which involves paraphrasing, summarizing, creating analogies, and posing and answering questions as well as methods for organizing information such as mapping and outlining. In distance courses, methods of learning are essential as learners do not have the benefit of face-to-face interaction with the instructor, who could provide additional guidance beyond what is available in the course, thus they need a variety of methods of learning to access and comprehend material on their own.

\subsubsection{Use of course materials}

In all courses, familiarity with the parts of the textbook, supplemental resources, the online course management system, and other resources are important, but for a distance course, this is critical. Learners must understand how the course is organized within a learning management platform, where to locate relevant course materials, and how to submit assignments. Teachers and classmates may not be readily accessible to answer questions. Methods of learning related to using the course materials set a strong foundation for the implementation of strategies leading to in-depth learning. Also relevant are good reading strategies as much information in a distance course is communicated through the written form.

In our course, learners examine a list of reading strategies and evaluate themselves on their ability to apply these strategies to their use of the course study guide and textbook. Examples of effective reading strategies include previewing assignments and due dates, predicting what comes next, writing down questions, taking notes, identifying main ideas, completing exercises, and measuring comprehension. As part of the self-evaluation, learners rate levels of ability related to each strategy - what they do always, sometimes, or neverand determine their strengths and weaknesses. They consider what has worked well for them in the past, what might be particularly effective in the distance course, and which strategies are new and need to be learned. They then set a related goal and indicate how they will begin to learn about and implement the strategy they have selected. The next step is to write a description of their experience with this activity in their learner journal. One learner commented: "The strategies I use are to find any reading helps in the study guide or text book (hints, objectives, definitions, boldface or italic print summaries, tables or figures), but not very often is to predict (guess) what will come in the next section." This learner recognizes a familiar strategy and one she could adopt in the future to improve her learning. The activity builds language skills-reading, writing, communicating-as well as self- 
regulated learning. Courses in any discipline can incorporate study strategy instruction and practice specifically designed to support learner success.

\subsubsection{Preferences for learning}

Another area that lends itself well to language acquisition and learning in general is increasing awareness of learning preferences. In our English language courses, learners complete an activity that helps them determine their preferred methods for gaining proficiency in English such as talking to friends, watching television, studying grammar, playing games, practicing English outside of class, interacting with friends or native speakers, having the teacher point out their mistakes, obtaining language input through reading or listening, or practicing pronunciation. These items are organized into sets, which are categorized according to learning types (i.e., authority, communicative, analytical, concrete) (e.g., see Scharle \& Szabó, 2000).

The categories are based on Gardner's $(1983,2004)$ multiple intelligences theory, which encompasses types of intelligences such as visual-spatial, bodily-kinesthetic, musical, linguistic, logical-mathematical, interpersonal, and intrapersonal, as well as on the personality dimensions of extraversion and introversion and preferred logic approaches (i.e., deductive, inductive). After the evaluation process, learners analyse their preferences and how this information can help them be a better student, language learner, and distance learner. As with the other activities, they reflect on their experience with the activity in their journals. The effectiveness of this activity is illustrated by the following journal excerpt, which also illustrates how this individual benefits from the social environment:

I like studying with people. The more people I have, the more understanding I gain. It means that working or studying with people is better than studying independently. ... For instance, my teacher assigns me to write a proposal about scholarship and I do not know how to write it. In this case, I need to ask for information from someone who knows how to do it. Those people will help me find the ideas and help me correct my drafts. ... When I work on a group assignment I never feel lost for ideas because my group members share their concepts. Moreover, I could get help from my team members when I need more explanation on any task. Another important point that I could get from my group is emotional support. ... . To sum up, self-study would never be my learning style.

A wide range of learning preference instruments are available or can be adapted to fit the needs of various courses and subject areas. As demonstrated by the English language learning example, surveys can be tailored to reflect content or skill areas. The Strategy Inventory for Language Learning (Oxford, 1990) is a useful resource for language learners to create awareness and expand knowledge of possibilities. More general learning preference measures can also be administered to help learners in all contexts understand how they learn (e.g., see http://www.lth3.k12.il.us/rhampton/mi/mi.html for multiple intelligences instruments). For distance learners, understanding their learning preferences can help them make appropriate choices related to course options and strategies needed for mastery of the material.

\subsubsection{Time}

The dimension of time involves managing time, avoiding procrastination, and prioritizing activities. Learners who manage their time well have better academic achievement, higher 
self-esteem, and a greater sense of competence than those who do not (Dembo \& Eaton, 2000; Dembo \& Seli, 2008). When effective time management results in achievement of learning outcomes, learners have positive feelings about themselves and their abilities. This reinforces their motivation to make effective use of their time and apply themselves to their studies. Procrastination can be a way for learners to protect their identity from failure (Ferrari, 1991). If a learner procrastinates and gets a poor grade, the learner can attribute it to lack of time rather than lack of ability. Time use strategies include working on a task for a short period of time rather than ignoring it, thus building momentum to continue working (Ellis \& Knaus, 1977), and changing dishonest self-talk (Ferrari, Johnson, \& McKown, 1995). The latter involves not convincing oneself that it is too late to complete a task or that one does one's best work at the last minute. A more positive approach is to tell oneself that it is not too late to start and that time is important to doing a thorough job on a task. This type of self-talk results in improved attitudes, motivation, and behaviour. Learners can improve their use of time through instruction. This is particularly critical to success in a distance course as learners are largely on their own to set goals, manage and complete assignments, divide learning tasks into manageable parts, and determine their own schedules.

\subsubsection{A record of time use}

To help our learners recognize how they use their time, they engage in an activity in which they record their activities for a 24-hour period. Then they analyse their use of time-how they used it, what surprised them, what they learned, how they waste time, and where they could find more study time. They write about their findings in their journals. For some, this straightforward activity is a real eye-opener. One learner reported the following:

While I am keeping track of my activities for 24 hours, I learned that "Time is a precious thing." From this activity, I am able to know what I did in a whole day. I can see my worst time and my best time. For example, I used most of my time for watching TV; sleeping at evening time; teaching my nephew; going to my friend's house; and reading the student guide. And what surprises me? Watching TV and sleeping at evening time took more of my day than I expected.

A variation to the exercise is to ask learners to organize their use of time into categories. Categories might include essential things (eating, sleeping, working), necessary things (spending time with family, caring for loved ones), and nice-to-do things (sports, watching television, hobbies, visiting with friends) (categories adapted from Beck, 2010). What individuals consider essential, necessary, and nice-to-do will vary, but this exercise helps them prioritize and manage their time. They can then plan how they will use their time in the next week, and list and prioritize their activities based on the categories. At the end of the week, they evaluate and revise their plan for the next week as needed.

\subsubsection{Time use strategies}

Strategies for time use are also critical to success in distance learning courses. Although these are important in all learning contexts, distance courses have greater flexibility, thereby giving learners more autonomy over when and for how long to study. The lack of a structured schedule, however, can lead to procrastination and be a deterrent to success. Learners may have limited dialogue with the instructor and other learners, and course structure may be loose in some cases, thus learners must determine how much time is 
needed to complete assignments and how to plan and schedule related tasks. The following list provides some general guidelines for use of time (adopted from Dembo \& Seli, 2008).

- Set a regular daily study time, as though attending a face-to-face class.

- Determine what to work on during the study time-reading, review, specific assignments, or interaction activities.

- Evaluate the level of difficulty and amount of time needed for tasks - those that are easy and can be done quickly and those that are more difficult and will take more time. Begin difficult tasks and those that will take more time early. Break them into steps and work on them incrementally. For example, writing a research paper involves finding relevant articles, reading and taking notes, synthesizing ideas, drafting, formatting references, and so on. Decide ahead of time which of these tasks to work on during the set study time.

- Make use of short periods of available time to review notes, organize study materials, preview readings and exercises, plan, or do e-mail correspondence.

- Work ahead-look at the course assignments for the upcoming week and major assignments and their due dates. Complete what needs to be done and then continue to the next day's assignment. Aim to get ahead of schedule and begin working on major course assignments. Working ahead makes unexpected problems such as illness or minor emergencies more manageable.

These strategies can be shared with learners in pre-enrollment information, the course study guide, or instructor e-mails and announcements. In our course study guides, we include study tips related to the assignments. The tips are brief pointers to help learners approach tasks effectively and efficiently and improve success. Time use and other strategies can also be topics for pair and group interactions, writing assignments, or even be included on tests. For example, a bonus test question might be, "How did you manage your time to prepare for this test?" This helps learners reflect on their performance. As instructors reinforce the importance of all the dimensions of self-regulated learning, students will begin to understand and value them. They will develop the ability for effective learning and recognize strategies that are efficacious in distance learning contexts.

\subsubsection{Physical environment}

Distance learners must create their own learning and study spaces. They do not have the advantage of instruction in a classroom and may not have accessibility to a library or similar environment that is largely free from distractions as do traditional students. As such, the dimension of physical environment is of critical importance. This dimension involves the learner's ability to restructure the physical environment so that learning can be effective (Dembo \& Eaton, 2000; Dembo et al., 2006). Learners need to locate places to study that are quiet and free from distractions. Specific strategies for eliminating distractions might be turning off cell phones, e-mail notification alerts, music, and television. Learners may also want to identify a particular time of day most conducive to concentration. For some, this is early in the morning or late at night when they are free from responsibilities in the home. Others may decide to go to internet cafes to upload assignments at non-peak times to avoid the noise. Another consideration for distance learners is ensuring that they have sufficient computer skills to engage in the tasks in the course. If not, computer problems can distract from the ability to access and complete assignments. In addition to external distractors in 
the form of noise and interruptions, internal distractors such as personal concerns and anxieties also play a role. In both cases, learners must increase their awareness of where and why these distractors occur and take steps to eliminate them.

\subsubsection{Study behaviours}

Distance language learners in our courses who complete the initial self-assessment related to the six dimensions and determine that controlling the physical environment is one of their weak areas have the option of several related activities. One of these is to complete a chart in which they list the various places they study and what they do in this location (e.g., internet café-e-mail communications). They then view a series of statements describing how well they study in each location (e.g., I can work on my studies without being interrupted. I can begin studying immediately. I can concentrate.). They use a rubric with a score ranging from 1 to 5 depicting to what degree the statement describes their study behaviour. Next they respond to a series of questions guiding them in an analysis of their findings (e.g., Which location did I rate the best? Do I study well in more than one location? How can this information help me improve the places where I study?). The last step, as always, is to write a description of their experience with the activity in their journals. The value of this activity is indicated by one learner as follows:

For me, evaluating my study environment is so important to change the way of my study... . There are four study locations chosen for my environment evaluation such as at my office, at internet shop, my house, and my friend's office. . . . With no doubt, the evaluation showed me my high and low points in each location. In evaluation result, studying at my office gives me the lowest outcome in the above four places. . . . In reality, the answer from this evaluation will tell my poor study and guide me how to develop or change my study environment if I would like to get successful in my study.

\subsubsection{Attention and concentration}

Learners can also benefit from a better understanding of attention and concentration. Attention refers to controlling "awareness of events in the environment," and concentration to the "continual refocusing on a perceived stimulus or message" (Dembo \& Seli, 2008, p. 167). In other words, learners are attentive when they are not distracted by the environment or their own emotional and physical needs. They concentrate by continuing to refocus on a learning task. To improve ability in both areas and manage distractors, learners can be made aware of appropriate strategies and set goals for implementing and monitoring their use of these strategies. The following list of strategies is adopted from Dembo and Seli, 2008.

- Study in a designated area free from noise and distractions.

- Control distractions by making sure the space is physically comfortable (temperature, light, furniture) and that disruptions will not occur (leave an automated phone or email message indicating availability after a certain time, put a "do not disturb" sign on the door, etc.).

- Attend to physical needs by eating, drinking, or taking a short nap before studying. Avoid studying at times with increased likelihood of hunger and sleepiness.

- Alternate learning tasks and subject areas and take short breaks every hour.

- Resolve worries and concerns prior to studying if possible.

- Use active learning techniques such as asking questions, outlining, summarizing, notetaking, and mentally reviewing materials to increase concentration. 
- Set goals for what aspects of a task or assignment are to be accomplished in particular time frame.

- Have an overall plan for time use during the week, leaving blocks of time to work on specific courses or assignments.

As learners engage in the use of these strategies, they should continue to evaluate the challenges they have, the causes of these challenges, and the effectiveness of the strategies they are using, and make modifications in their study plans, time use, or physical environment as appropriate.

\subsubsection{Social environment}

The social environment aspect of self-regulated learning involves seeking help from social sources such as peers, instructors, and tutors, and non-social sources, including reference books, the textbook and study guide, and the internet (Dembo \& Eaton, 2000; Dembo \& Seli, 2008; Zimmerman \& Kitsantis, 1997). Self-regulated learners have the ability to determine when to work independently or seek help from others. They recognize when they have difficulty learning and need assistance and how collaboration with peers can be advantageous to completing learning tasks and accomplishing goals. They view seeking assistance as a positive strategy to help them learn successfully rather than viewing it as a negative reflection on their ability. When learners focus on mastery of the subject matter, set goals, and have positive views of their academic ability, they are more likely to seek help (Dembo et al., 2006). Learners need to acquire a positive attitude about seeking help and possess the necessary social skills to interact with other students effectively, work in groups productively, ask questions, and get help from their professors, tutors, and staff in learning support centers. The technology associated with distance learning readily supports and enhances use of the social environment and enables interaction and help-seeking. Online discussions, instructor office hours, shared narrated presentations, peer commentary on writing drafts, and various group projects are all relatively easy to accomplish, and can be used by course designers and instructors to create community among distance learners.

\subsubsection{Teach one another}

Learner attitudes toward help-seeking are important. Learners' educational and cultural backgrounds as well as their individual learning experiences affect their dispositions for seeking help. If they are accustomed to a system of competition and ranking related to learning, collaboration with peers may be unfamiliar and uncomfortable. Similarly, if they are not familiar with a free exchange of ideas and challenging the ideas of others (including those of the instructor), they may not value what other learners have to offer in terms of understanding course concepts.

The classroom environment-whether virtual or face-to-face-must be established as a safe space in which to ask questions, express lack of understanding, and share knowledge. This is supported in a distance learning environment as learners are separated physically, thereby creating a greater feeling of anonymity. However, one deterrent to establishing such an environment is when learners believe that all knowledge and information resides with the teacher and that they cannot learn from their peers, who lack expertise and experience. This perception must be overcome in order for the social environment to be an effective learning tool. 
One institution's model of distance learning is designed to encourage learner self-regulation. The learning model on which all courses are based encompasses three steps (Brigham Young University Idaho, 2007). First, learners prepare for discussion by reading and studying course materials for the unit. Next, they teach each other by posting questions in the online course management system and responding to the questions of their peers. They may have responsibility to lead a discussion on an issue related to the topic and to reply to a set number of posts from other learners. The instructor monitors the discussion and responds to individual learners but in a way that does not limit or take control of the interaction so as to allow the learners to process and understand the material together. The instructor encourages learners to solve problems collaboratively by directing them to seek help from each other. The last step is to ponder and evaluate the learning experience for the week. This step consists of responding to specific questions related to the content and its application, and reflecting on the overall learning experience and how it could be changed or improved in the upcoming week.

In keeping with the theory of transactional distance (Moore, 1972, 2007), mentioned earlier in connection with the model of self-regulated distance learning, the lesson design described has sufficient structure to guide learners and give them direction. It encourages dialogue among learners and the instructor. Learners are provided with choices to support their capacity for autonomy, or self-direction, and learn strategies for becoming self-regulated. The instructor models how to respond appropriately to discussion posts in a way that respects diverse positions and opinions rather than indicating if answers are right or wrong. In this way, learners begin to develop more confidence in their own abilities as learners and in the viability of help from their peers. The instructor also holds weekly live office hours using Adobe Connect, thus furthering opportunities for dialogue.

\subsubsection{Tutorial preparation}

Learners can show responsibility for their learning by preparing for appointments with tutors and instructors, regardless of whether these appointments are face-to-face or through technology. In our distance language learning courses, learners have a weekly live tutorial session. To make this use of the social environment more efficacious, learners complete a worksheet that outlines the steps they need to take related to the appointment: be prepared, participate, ask questions, and practice. Being prepared focuses on doing the assignments for the week, writing down related questions to ask in the tutoring session, and making note of the date and time for the appointment. The steps of participating and asking questions involve making the learners aware that this is an opportunity for them to practice their speaking skills and having them record three things that they learned or found interesting from the session as a result of asking questions. The final step, practice, focuses on learners identifying two things they understand better as a result of the session and how they will use what they learned to improve their language proficiency. Similar steps can be followed for interacting with the instructor during office hours or collaborating with peers on assignments.

After the tutor session, learners compare how they prepared for appointments in the past with how they prepared when guided by the steps, how they can practice the skills learned in the session, and what they can do next time to prepare for their appointment. Thus they are reflecting, monitoring their performance, and setting and revising their goals. The effectiveness of this assignment is demonstrated by the following learner quotation: 
Tutor session is one of my favorite parts. This is the time where I can practice my English, in speaking and listening. Before meeting and talking to my tutor, I did prepare myself by reading the assignment and read things that I'm going to talk to my tutor. . . . My tutor will give time to ask on things that I do not know, she will give me opportunity to share my ideas, or tell something on the topic. . . . Even I can learn something else like new phrases and words from her while she's speaking or the correct pronunciation. I'm not ashamed to ask her on things I do not know. I think this is a great opportunity for us as distance learners. My tutor also reminds me to do the home works and ask me to email the teacher or her when I have problems or difficulties during the course. I'm so grateful and thankful for my tutor. She's a great support to me.

\subsubsection{Performance}

The dimension of performance involves self-observation and evaluation. It is an on-going process as learners increase awareness of self-regulation, select and implement strategies, compare goals with achievement, and determine the effectiveness of their methods of learning. They need to ensure that their self-appraisals are accurate, as denial of the need to change will result in no improvement (Dembo \& Eaton, 2000). As instructors guide learners, they must encourage or require them to apply new methods of learning rather than reverting to those that are familiar.

The concept of metacognition, defined as "thinking about thinking" (Anderson, 2002, p. 2), has some overlap with the dimensions of self-regulated learning, and particularly, the dimension of performance. Similar to performance, metacognition connects various aspects of effective learning with an evaluative procedure. Metacognition has been described as a five-stage recursive process that involves preparing and planning, selecting and using appropriate strategies, monitoring, orchestrating, and evaluating (Anderson, 2002). The first stage involves setting goals and sub goals (cf. motive). Goal achievement depends on selecting appropriate strategies and knowing when to apply them (cf. methods of learning). As learners monitor their performance, or think about how they think and learn, they determine which methods are most appropriate and effective (cf. performance). They also orchestrate the use of strategies by applying multiple methods of learning and making associations among them (cf. methods of learning).

The evaluation stage (cf. performance) involves four parts which correspond to and assess learner effectiveness related to all five stages of metacognition. Learners review what they want to accomplish (preparing and planning), the strategies they are using (selecting and using appropriate strategies), their usefulness (monitoring), and additional strategies that may prove effective (orchestrating). The six dimensions of self-regulated learning as compared to the five stages of metacognition are broader in scope (i.e., cognition, metacognition, motivation, and behaviour) and specify additional categories (i.e., physical and social environment, time). These components are extremely relevant to distance learning. The stages of metacognition are useful, however, in conceptualizing how learners can think about the way they learn, and as such, are relevant to the dimension of performance. As with the stages of metacognition, the six dimensions of self-regulated learning are recursive. As learners set goals, apply strategies, consider their environment and use of time, they are continually reflecting, monitoring, and evaluating their performance. 


\subsubsection{Learning plans}

As part of the process of becoming self-regulated, learners should formulate a learning plan. This can be initiated as they consider their purposes for learning; identify their strengths and weaknesses through self-analysis and reflection; select and apply strategies related to learning, time, and physical/social environment; and consider the degree to which their performance results in goal achievement. Such a learning plan should involve four cyclical steps: self-observation and evaluation (i.e., identification of problems related to learningwhen, where, how often; effects of the problem; and contributing factors), goal setting and strategic planning (i.e., selection of strategies and when to use them), strategy implementation and monitoring (strategies used, when, how recorded and monitored, changes made), and strategic-outcome monitoring (Dembo \& Seli, 2008). The last stage involves asking questions such as "Did I accomplish my goal?" "Which strategies were the most and least helpful?" "What adjustments do I need to make?"

The ultimate goal of all of the activities and strategies provided to learners in a course is to develop their ability to regulate, or take responsibility for, their learning behaviours rather than the teacher monitoring progress (Dembo et al., 2006). A learning plan might consist of checklists, progress logs, tally sheets, or charts. In our distance language learning courses, learners chart their increases in reading speed and comprehension, track grammatical errors marked on their papers to find recurring weaknesses, and complete listening logs that provide a summary sentence and document the source of the material, length of time involved, and the number of times they listened to the excerpt. Learners also receive completed rubrics and feedback sheets from tutors and instructors. Similar activities and approaches can occur in any course to help learners monitor their progress, and make use of teacher feedback, comments, or test scores. The learning plan can take a variety of formats and encompass different sources of information, but at minimum, should be a record of goals and sub goals related to a learning challenge, strategies used, progress made, goal revisions, and goal achievement.

\subsubsection{Reflective journal}

Each self-regulated learning activity in our English language courses involves monitoring and evaluating performance. As learners complete a self-assessment or activity related to one of the dimensions of self-regulated learning, they are guided through a set of structured questions, rubrics, or charts designed to help them analyse their performance. Additionally, after completing all of the steps related to the activity, including the analysis stage, they write in their journals about the experience they had with the activity and what they learned from it. The instructor provides commentary on the journal entries, being careful to not give directives or make critical or judgmental remarks. The goal of the journal is to evaluate performance. Similar measures of performance might include think aloud protocols in which learners record (verbally or in writing) their thought processes as they perform a task with the goal of identifying reasons for their choices (e.g., see Anderson, 2004).

The journal also provides practice with written English. It is an authentic communicative situation in which the learner is conveying information to an audience. The learner is also applying and practicing good writing techniques, thereby reinforcing what has been taught in the course. In any distance course, writing is a useful method of learning in that it provides learners with the experience of expressing what they know about a topic. This act 
of expression aids long-term memory of the ideas and content and also serves to help learners identify what aspects of the content may need to be reviewed or better understood. The following excerpt from a learner's journal demonstrates increased awareness as a result of the dimension of performance:

Time goes very fast. It is good for me to look back. My time management is better than before. Since I can plan my time more useful. It gives me a great power after finishing all my work after following the timetable. Second, I can put more attention on my study, since I have a good environment that is my bedroom. It is tidy for me to study and do my homework. After cleaning my bedroom, it is easy for me to find out some useful English book to study. I am sure I will use these method to improve my English ... . Although sometime I will be tired, I still get more power to go forward. Since I can feel satisfy after improve my study means.

\section{Conclusion}

This chapter has reviewed key findings from the literature on self-regulated learning and autonomy and applied them to distance learning. In particular, it has presented a model for self-regulated distance learning and research findings supporting the model. Example activities have been provided to demonstrate how the model can be applied to help distance learners develop strategies related to the six dimensions of self-regulated learning: motive, methods of learning, time, physical environment, social environment, and performance. In the case of English language learning courses, the use of embedded self-regulated learning activities results in improved language proficiency, satisfied learners, and increased capacity for self-regulation and autonomy. The pedagogy incorporated by this innovative course design model addresses the dual needs of learners to master content and develop learning skills and strategies. The latter allows learners to be successful in achieving their goals. The model does not prescribe specific pedagogical activities; these can be developed to fit the context and learner using the six dimensions of self-regulated learning as guidelines.

\section{Acknowledgment}

I would like to acknowledge Dr. Ellen Bunker, her course design team, and the distance learning course instructors in the English as an International program at Brigham Young University Hawaii for their vision and diligent efforts in designing and teaching courses that support the development of self-regulation and student success.

\section{References}

Anderson, N. J. (2002). The Role of Metacognition in Second Language Teaching and Learning. ERIC Clearinghouse on Languages and Linguistics (ED No. 463659), Washington, DC

Anderson, N. J. (2004). Developing metacognitive awareness, In: Extensive Reading Activities for Teaching Language, J. Bamford, \& R. R. Day, (Eds.), pp. 175-180. Cambridge University Press

Andrade, M. S., \& Bunker, E. L. (2011a). Developing Self-Regulated Distance Language Learners: A Promising Practice. Proceedings of the Fourth Annual Self-Regulated Learning in Technology Enhanced Learning Environments, Barcelona, Spain

Andrade, M. S., \& Bunker, E. L. (2009). Language learning from a distance: A new model for success. Distance Education, 30, 1, pp. 47-61 
Andrade, M. S., \& Bunker, E. L. (2011b). The role of self-regulated learning and TELEs in distance education - Narrowing the gap. In: Fostering Self-Regulated Learning Through ICTs, G. Dettori \& D. Persico, (Eds.), pp. 105-121. Hershey, PA: IGI Global

Beck J. B. (2010, April 29). Choose ye this day to serve the Lord. Proceedings of the 2010 BYU Women's Conference, Provo, Utah, April 29-30. Available from: http://lds.org/library/display/0,4945,9118-1-5187-1,00.html

Bothma, F., \& Monteith, J. L. dK. (2004). Self-regulated learning as a prerequisite for successful distance learning, South African Journal of Education, 24, 2, pp. 141-147

Brigham Young University Idaho. (2007). Learning Model. Brigham Young University Idaho, Rexburg, Idaho

Chang, M. M. (2005). Applying self-regulated learning strategies in a web-based instruction - An investigation of motivation perception. Computer Assisted Language Learning, 18(3), 217-230

Chen, P. D., Gonyea, R., \& Kuh, G. (2006). Learning at a distance: engaged or not? Innovate, 4, 3, pp. 1-7, Available from: http://innovateonline.info/pdf/vol4_issue3/

Learning_at_a_Distance-_Engaged_or_Not_.pdf

Dembo, M. H., \& Eaton, M. J. (2000). Self-regulation of academic learning in middle-level schools. Elementary School Journal, 100, 5, pp. 473-490

Dembo, M. H., \& Seli, H. (2008). Motivation and Learning Strategies for College Success: A SelfManagement Approach (3rd ed.). Lawrence Erlbaum, New York

Dembo, M. H., Junge, L.G., \& Lynch, R. (2006). Becoming a self-regulated learner: Implications for web-based education. In: Web-based learning: Theory, research, and practice, H. F. O’Neil, \& R. S. Perez, (Eds.), pp. 185-202. Lawrence Erlbaum Associates, Mahwah, New Jersey

Ellis, A. \& Knaus, W. J. (1977). Overcoming Procrastination. New American Library, New York

Ferrari, J. R. (1991). Self-handicapping by procrastinators: Protecting self-esteem, social esteem, or both? Journal of Research in Personality, 25, pp. 245-261

Ferrari, J. R., Johnson, J. L., \& McCown, W. G. (1995). Procrastination and Task Avoidance: Theory, Research, and Treatment. Plenum, New York

Gardner, Howard. (1983, 2004). Frames of Mind: The Theory of Multiple Intelligences. Twentieth Anniversary Edition. Basic Books, New York

Garrison, R. D. (2003). Self-directed learning and distance education. In: Handbook of Distance Education, M.G. Moore \& W.G. Anderson, (Eds.), pp. 161-168. Lawrence Erlbaum, Mahwah, New Jersey

Holec, H. (1981). Autonomy and Foreign Language Learning: Council of Europe. Pergamon Press, Oxford

Hurd, S. (1998a). Autonomy at any price? Issues and concerns from a British HE perspective. Foreign Language Annals, 31, 2, pp. 219-230

Hurd, S. (1998b). “Too carefully led or too carelessly left alone?" Language Learning Journal, 17 , pp. $70-74$

Hurd, S. (2000). Helping learners to help themselves: The role of metacognitive skills and strategies in independent language learning. In: Current trends in modern language provision for non-specialist linguists, M. Fay, \& D. Ferney, (Eds.), pp. 36-52. London: The Centre for Information on Language Teaching and Research (CILT) in association with Anglia Polytechnic University (APU)

Hurd, S. (2005). Autonomy and the distance language learner. In : Distance Education and Languages: Evolution and Change, B. Holmberg, M. Shelly, \& C. White, (Eds.), pp. 119. Multilingual Matters, Clevedon, United Kingdom 
Hurd, S. (2006). Towards a better understanding of the dynamic role of the distance language learning: Learner perceptions of personality, motivation, roles, and approaches. Distance Education, 27, 3, pp. 303-329

Krashen, S. (1985). The Input Hypothesis: Issues and Implications. Longman, London

Little, D. (1991). Learner Autonomy 1: Definitions, Issues, and Problems. Authentik, Dublin

Long, M. (1996). The role of the linguistic environment in second language acquisition. In : W. Ritchie, \& T. Bhatia, (Eds.), Handbook of Second Language Acquisitions, pp. 413468. Academic Press, San Diego, California

Moore, M. G. (1972). Learner autonomy: The second dimension of independent learning. Convergence, 5, 2, pp. 76-88. Available from: http://www.ajde.com/Documents/ theory.pdf

Moore, M. G. (2007). The theory of transactional distance. In : Handbook of Distance Education, M. G. Moore, (Ed.), 2nd ed., pp. 89-105. Lawrence Erlbaum, Mahwah, New Jersey

Murphy, L. (2005). Critical reflection and autonomy: A study of distance learners of French, German and Spanish. In : Distance Education and Languages: Evolution and Change, B. Holmberg, M. Shelley, \& C. White, (Eds.), pp. 20-39. Multilingual Matters, Clevedon, United Kingdom

Oxford, R.L. (1990). Language Learning Strategies: What Every Teacher Should Know. Heinle \& Heinle, Boston

Parsad, B., \& Lewis, L. (2008). Distance Education at Degree-Granting Postsecondary Institutions: 2006-07. National Center for Education Statistics, U.S. Department of Education

Scharle, À, \& Szabó, A. (2000). Learner Autonomy: A Guide to Developing Learner Responsibility. Cambridge University Press

Schunk, D. H. \& Zimmerman, B. J. (Eds.). (1994). Self-Regulation of Learning and Performance. Lawrence Erlbaum, Hillsdale, New Jersey

Swain, M. (1995). Three functions of output in second language learning. In: For H.G. Widdowson: Principles and practice in the study of language, G. Cook, \& B. Seidlhofer, (Eds.), pp. 125-144. Oxford University Press

Thang, S. M. (2005). Investigating Malaysian distance learners' perceptions of their English proficiency courses. Open Learning, 20, 3, pp. 243-256

Tobias, S. (2006). The importance of motivation, metacognition, and help seeking in webbased learning. In : Web-Based Learning: Theory, Research, and Practice, H. F. O'Neil, \& R. S. Perez, (Eds.), pp. 203-220. Lawrence Erlbaum, Mahwah, New Jersey

Uchtdorf, D. F. (2006, April). The power of a personal testimony. Ensign. Available from : http://lds.org/ensign/2006/11/the-power-of-a-personal-testimony?lang=eng

van den Boom, G., Paas, F., van Merrienboer, J. J. G. (2007). Effects of elicited reflections combined with tutor or peer feedback on self-regulated learning and learning outcomes. Learning and Instruction, 17, pp. 532-548

Vanijdee, A. (2003). Thai distance English learners and learner autonomy. Open Learning, 18, 1, pp. $75-84$

White, C. (2003). Language Learning in Distance Education. Cambridge University Press

Zimmerman, B. J. (1994). Dimensions of academic self-regulation: A conceptual framework for education. In : Self-regulation of learning and performance, D. H. Schunk \& B. J. Zimmerman, (Eds.), pp. 3-21. Lawrence Erlbaum, Hillsdale, New Jersey

Zimmerman, B. J., \& Risemberg, R. (1997). Self-regulatory dimensions of academic learning and motivation. In G. D. Phye (Ed.), Handbook of academic learning: Construction of knowledge, pp. 105-125. Academic Press, San Diego, California 


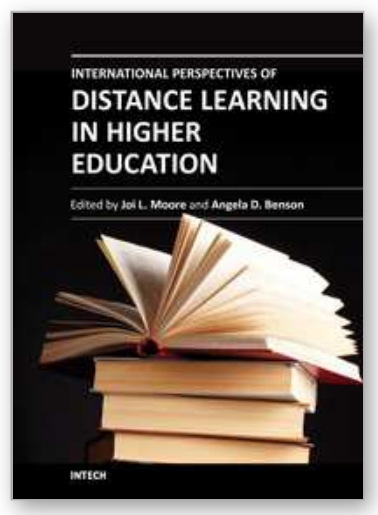

\author{
International Perspectives of Distance Learning in Higher \\ Education \\ Edited by Dr. Joi L. Moore
}

ISBN 978-953-51-0330-1

Hard cover, 332 pages

Publisher InTech

Published online 16, March, 2012

Published in print edition March, 2012

This book, written by authors representing 12 countries and five continents, is a collection of international perspectives on distance learning and distance learning implementations in higher education. The perspectives are presented in the form of practical case studies of distance learning implementations, research studies on teaching and learning in distance learning environments, and conceptual and theoretical frameworks for designing and developing distance learning tools, courses and programs. The book will appeal to distance learning practitioners, researchers, and higher education administrators. To address the different needs and interests of audience members, the book is organized into five sections: Distance Education Management, Distance Education and Teacher Development, Distance Learning Pedagogy, Distance Learning Students, and Distance Learning Educational Tools.

\title{
How to reference
}

In order to correctly reference this scholarly work, feel free to copy and paste the following:

Maureen Snow Andrade (2012). Self-Regulated Learning Activities: Supporting Success in Online Courses, International Perspectives of Distance Learning in Higher Education, Dr. Joi L. Moore (Ed.), ISBN: 978-953-510330-1, InTech, Available from: http://www.intechopen.com/books/international-perspectives-of-distancelearning-in-higher-education/self-regulated-learning-activities-supporting-success-in-online-courses-

\section{INTECH}

open science | open minds

\author{
InTech Europe \\ University Campus STeP Ri \\ Slavka Krautzeka 83/A \\ 51000 Rijeka, Croatia \\ Phone: +385 (51) 770447 \\ Fax: +385 (51) 686166 \\ www.intechopen.com
}

\author{
InTech China \\ Unit 405, Office Block, Hotel Equatorial Shanghai \\ No.65, Yan An Road (West), Shanghai, 200040, China \\ 中国上海市延安西路65号上海国际贵都大饭店办公楼 405 单元 \\ Phone: +86-21-62489820 \\ Fax: $+86-21-62489821$
}


(C) 2012 The Author(s). Licensee IntechOpen. This is an open access article distributed under the terms of the Creative Commons Attribution 3.0 License, which permits unrestricted use, distribution, and reproduction in any medium, provided the original work is properly cited. 